\title{
Acute burst fracture in Kummell's disease with acute onset neurological deficit: a case report on role of spinal stability and technical notes on "pivot ligamentotaxis"
}

Hyeun Sung Kim ${ }^{1 *}$ DD, Ravindra Singh ${ }^{1}$, Nitin Maruti Adsul', Sung Woon Oh'1, Jung Hoon Noh'1, Jun Hwan Park², I. L. Tae Jang ${ }^{1}$ and Seong Hoon $\mathrm{Oh}^{3}$

\begin{abstract}
Background: Kummell's Disease has insidious progression. Neurological deficit is usually slow in onset and progression and only few cases of acute neurological deficit have been reported. We came across a case of Kummell's disease which progressed to burst fracture, developed neurological deficit within two weeks. We managed patient with "pivot ligamentotaxis" and Polymethylmethacrylate augmented, posterior compressed, short segment percutaneous pedicle screw fixation.

Case presentation: Eighty-three years old woman following fall was on conservative management at another hospital. She had no neurological deficit. A week later her back pain aggravated and two weeks later developed bilateral buttock pain, bilateral lower limb weakness and diminished sensation in the sacral area.

Radiological investigations (X-rays, Magnetic resonance imaging and Computed tomography) showed L1 vertebral body fracture with vacuum cleft and fracture fragment retropulsed into the spinal canal.

A diagnosis of Kummell's disease with burst fracture of L1 vertebra \& neurological deficit was made.

Patient was managed with Polymethylmethacrylate augmented, posterior compressed, short segment percutaneous pedicle screw fixation. The reduction of the retropulsed fragment was achieved by virtue of "Pivot ligamentotaxis". The patient got relieved of the symptoms (Preoperative VAS 8 and postoperative VAS 3) and was allowed brace assisted ambulation on first postoperative day.

Conclusion: This study reports acute occurrence of the burst fracture in unstable vertebra inflicted by Kummell's disease and role of spinal stability in recovery. We achieved closed reduction of the fracture fragments and relief of the cord compression by posterior compression with "pivot ligamentotaxis".
\end{abstract}

Keywords: Kummell's disease, Neurological deficit, Burst fracture, Polymethylmethacrylate augmented, posterior compressed, short segment percutaneous pedicle screw fixation (PA-SSPPF), Pivot ligamentotaxis

\footnotetext{
* Correspondence: neurospinekim@gmail.com

'Department of Neurosurgery, Nanoori Hospital, Seoul, 731, Eonju-ro,

Gangnam-gu, Seoul, Republic of KoreaZIP-06048

Full list of author information is available at the end of the article
}

C The Author(s). 2019 Open Access This article is distributed under the terms of the Creative Commons Attribution 4.0 International License (http://creativecommons.org/licenses/by/4.0/), which permits unrestricted use, distribution, and reproduction in any medium, provided you give appropriate credit to the original author(s) and the source, provide a link to the Creative Commons license, and indicate if changes were made. The Creative Commons Public Domain Dedication waiver (http://creativecommons.org/publicdomain/zero/1.0/) applies to the data made available in this article, unless otherwise stated. 


\section{Background}

The osteoporotic vertebral compression fractures and Kummell's disease (KD) have become common [1, 2]. Kummell's disease is a disease caused by osteonecrosis and can lead to severe vertebral collapse, which can lead to severe pain and may progress to neurological deficit $[1,3]$. Neurological deficit in KD usually progresses slowly. Two cases of acute neurological deficit in KD have been reported $[4,5]$. We report a case with acute occurrence and progression of neurological deficit in early phase of $\mathrm{KD}$ associated with burst fracture of the vertebral body which was managed by reduction using "pivot ligamentotaxis" and Polymethylmethacrylate augmented posterior compressive, short segment percutaneous pedicle screw fixation. The neurological status was restored after stabilization.

\section{Case presentation}

\section{Case History}

Eighty-three years old woman following a fall was put on conservative management at another hospital. Initially her physical examination was mostly normal other than spinal tenderness and she had no neurological (Sensory or motor) deficit. A week later she started having severe back pain and two weeks later she also developed bilateral buttocks pain, bilateral lower limb weakness and had diminished sensation in the sacral area.

\section{Physical Examination}

Revealed severe tenderness at thoracolumbar junction and neurologic examination demonstrated grade 4/5 strength in the lower extremities. Sacral sensation decreased, bladder and bowel function was intact.

\section{Investigations}

Initial magnetic resonance imaging (MRI) revealed vertebral compression fracture of L1 body without burst and no canal compromise (Figs. 1a \& 2a). One week later the MRI and computed tomography (CT) revealed compression fracture with intravertebral cleft and beginning of the burst of the vertebral body. A fragment was retropulsed into the canal (Figs. 1b, b2, and 2b). An MRI two weeks from initial fall shows aggravation of the burst fracture and thecal sac compression (Figs. 1c \& 2c). A diagnosis of Kummell's disease at L1 vertebra with burst fracture of the body with spinal canal compromise and neurological deficit was made.

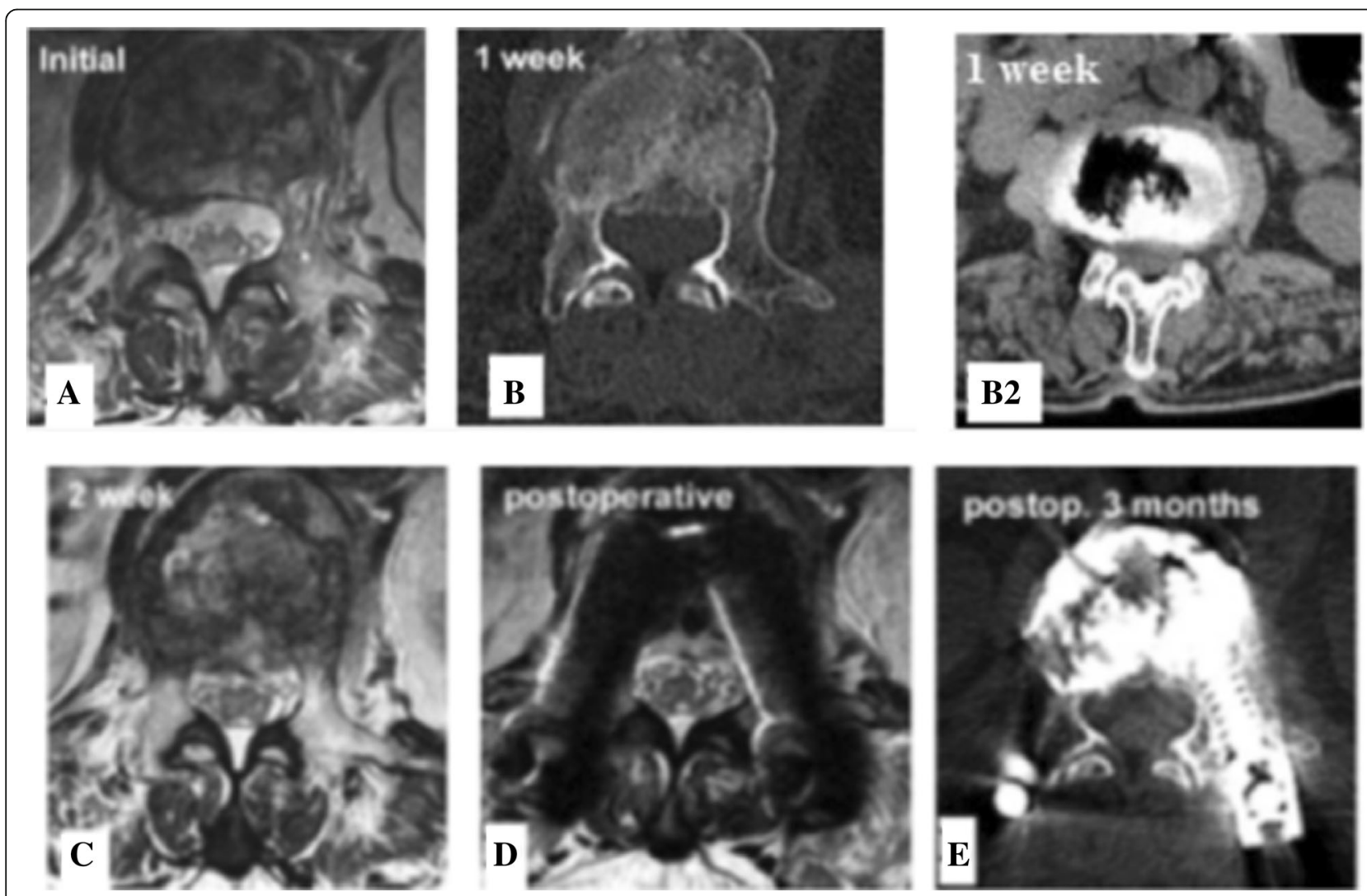

Fig. 1 Axial MRI \& CT Showing Rapid Progression and Resolution of Burst Fracture and Compression in a case of Kummell's Disease. a Initial MRI, b1 MRI at 1 week, b2 CT at 1 week, c MRI at 2 week, d Post-operative MRI, e Postoperative CT 3 months 

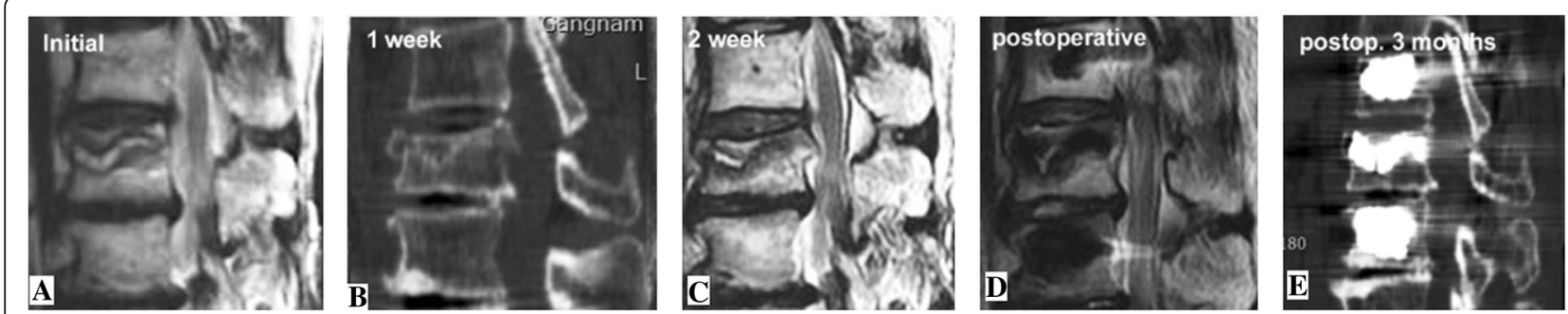

Fig. 2 Sagittal MRI Showing Rapid Progression and Resolution of Burst Fracture and Compression in a case of Kummell's Disease. a Initial MRI, $\mathbf{b}$ MRI at 1 week, $\mathbf{c}$ MRI at 2 week

\section{Treatment}

Polymethylmethacrylate (PMMA) augmented posterior compressive, short segment percutaneous pedicle screw (PA-SSPPF) fixation was done at T12, L1 and L2 vertebrae levels. Postoperatively the height of L1 body was restored and thecal compression disappeared (Figs. 1d \& 2d). The patient experienced significant pain relief (Preoperative VAS 8 and postoperative VAS 3) and could ambulate with a brace on first postoperative day. Three months later the vertebral body height, stability was well preserved and patient had no neurological deficit (Figs. 1e \& 2e).

\section{Pivot Ligamentotaxis}

Is a novel concept in minimally invasive spine surgery (MISS). In our case the left pedicle screws of the T12, L1 \& L2 were inserted first followed by the right screw of the L1 vertebra. Using the inserter the rod was slide through the pedicle screws on right side. Rod blockers of T12 pedicle screw was tightened first then T12 \& L1 pedicle screws compressed and with the help of the compressor placed horizontally a cranially distractive force applied using left L1 pedicle screw as pivot points and the rod blockers of the right L1 pedicle screw tightened. This maneuver is repeated with of L1 and L2 where a caudally directed distractive force was applied using L1 pedicle as pivot. The cumulative result of this maneuver was ligamentotaxis and reduction of the retropulsed fragment Figs. 1d, 2d, and 3a \& b). This was followed by insertion of remaining two contralateral pedicle screws and fixation. As described earlier all the screws were PMMA augmented inserted using minimally invasive screw insertion technique.

\section{Discussion and conclusion}

Not many cases of Kummell's disease associated with neurological deficit have been reported and a few reports of KD patients who presented with early onset and acute neurological deficit $[4,5]$. However, we could not find
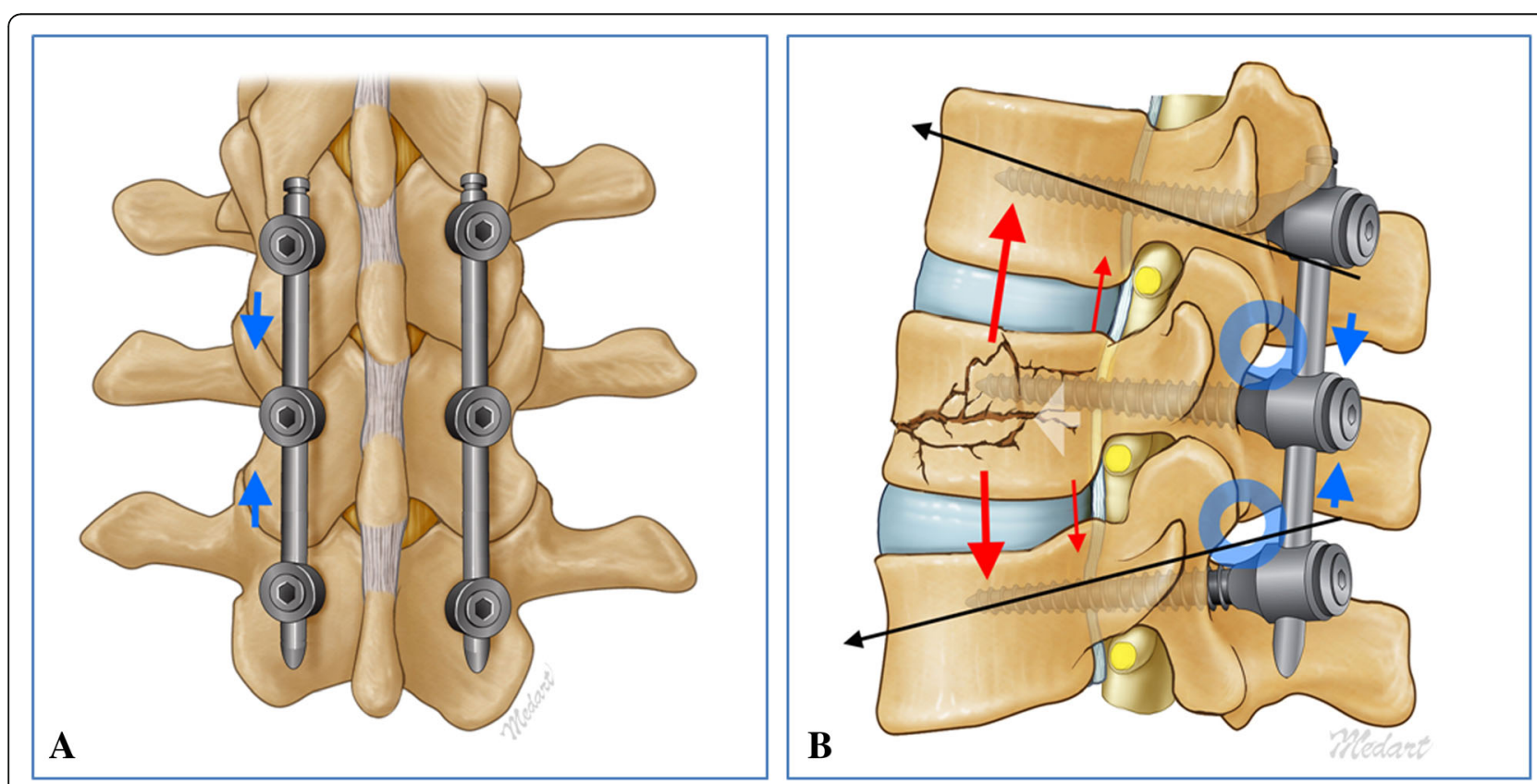

Fig. 3 a Coronal and b Sagittal images showing the mechanism of "Pivot ligamentotaxis" 
any study or case report which mentions acutely occurring burst fracture of the involved vertebra as inciting event for the neurological compromise.

The dynamic instability at the vertebral body fracture adversely affects the fracture union, promotes vascular compromise which may result into psuedarthrosis and osteonecrosis $[1,2,6]$. Thus spinal instability has a role to play in the progression of the Kummell's disease a fact supported by our study. Kim et al. had proposed Spinal Instability Predictive Score (SIPS) for KD patients with vertebroplasty which scores and grades instability [2]. There is no such score to predict the progression from osteoporotic vertebral fracture to the Kummel's disease.

Conservative treatment for $\mathrm{KD}$ includes bed rest, brace, pain relief and osteoanabolic therapy (e.g. Bisphosphonates and Teriperatide) $[1,3]$.

Various surgical modalities are summarized in comprehensive review by Formica $\mathrm{M}$ et al. [1]. Laminectomy, and hematoma removal mentioned for neurological deficit associated with intraspinal hematoma $[4,5]$. Bone cement augmented percutaneous pedicle screw stabilization also has good results in Kummell's disease [7, 8].

We performed PMMA augmented, posterior compressed, percutaneous short segment pedicle screw fixation (PA-SSPPF) involving T12, L1, L2 vertebrae. The patient improved rapidly in postoperative period with the magnetic resonance imaging (MRI) showing resolution of canal compromise. Fast recovery of the patient can be attributed to the spinal stability achieved following fixation. We could reduce the fracture fragments into place and relieve thecal sac compression by applying posterior compression. This reduction was possible due to pivoting around the contralateral pedicle and we name this phenomenon as "pivot ligamentotaxis". The pivot ligamentotaxis converts compression applied posterior into ligamentotaxis forces in the ligaments anterior to the facet joints e.g. posterior longitudinal ligaments (PLL) and anterior longitudinal ligaments (ALL) by virtue of pivoting around the facet joints.

This study shows that the neurological status can deteriorate rapidly following burst fracture of the involved vertebral body. The expeditious deterioration and prompt recovery of the patient affirms the role of spinal stability in the pathogenesis of burst fracture in KD and neurological deficit. "Pivot ligamentotaxis" allowed us to achieve closed reduction of fracture and decompression of the thecal sac. However, a study with larger sample and longer follow up would be required to derive a significant conclusion. In addition, the concept of "pivot ligamentotaxis" needs further evaluation with biomechanical studies. Also there is need for a predictive scoring system which could predict the possibility of progression of vertebral compression fracture to Kummell's disease and occurrence of burst fracture at the earliest stage, so that appropriate measures could be taken.

\section{Abbreviations}

ALL: Anterior longitudinal ligament; CT: Computed tomography;

KD: Kummell's disease; MISS: Minimally invasive spine surgery; MRI: Magnetic resonance imaging; PA-SSPPF: Polymethylmethacrylate augmented, posterior compressed, short segment percutaneous pedicle screw fixation; PLL: Posterior longitudinal ligament; PMMA: Polymethylmethacrylate; SIPS: Spinal instability predictive score; VAS: Visual analogue score

\section{Acknowledgements}

We would like to acknowledge scientific team members Ms. Jae Eun Park and Mr. Kyeong-rae Kim for providing assistance in acquiring full text articles and managing digital works.

\section{Funding}

No funds were received in support of this study. No benefits in any form have been or will be received from a commercial party related directly or indirectly to the subject of this manuscript.

\section{Availability of data and materials}

All data generated or analyzed during this study are included in this published article (and its supplementary information files).

\section{Authors' contributions}

All the authors have contributed significantly to the concept, design, data acquisition \& analysis and drafting the manuscript for this work. All the authors have given final approval for the article to be published and have agreed to be accountable for all aspects of the work. All the authors satisfy the ICMJE criteria for authorship. HSK is the corresponding author and has contributed significantly to the concept, design, data acquisition \& analysis and drafting of the manuscript for this work. He has also given final approval of the version to be published. RS has contributed significantly to the concept, design, data acquisition \& analysis and drafting of the manuscript for this work. NMA has contributed significantly to the concept, design, data acquisition \& analysis and drafting of the manuscript for this work. SWO has contributed significantly to the concept, design, data acquisition \& analysis for this work. JHN has contributed significantly to the concept, design, data acquisition \& analysis for this work. JHP has contributed significantly to the drafting the work or revising it critically for important intellectual content. ITJ has major contribution to the conception or completion of the manuscript. SHO has major contribution to the conception or completion of the manuscript.

\section{Ethics approval and consent to participate}

The patient had consented in written for participation in the study with prior approval of the Nanoori Hospital's human research ethics committee.

\section{Consent for publication}

The patient had consented in written for the publication of the case report along with participant's data in any form (including images).

Competing interests

The authors declare that they have no competing interests.

\section{Publisher's Note}

Springer Nature remains neutral with regard to jurisdictional claims in published maps and institutional affiliations.

\section{Author details}

${ }^{1}$ Department of Neurosurgery, Nanoori Hospital, Seoul, 731, Eonju-ro, Gangnam-gu, Seoul, Republic of KoreaZIP-06048. ${ }^{2}$ Medical School University of Debrecen, Debrecen, Hungary. ${ }^{3}$ Department of Neurosurgery, Nanoori Incheon Hospital, Incheon, Republic of Korea.

Received: 25 September 2018 Accepted: 25 April 2019

Published online: 14 May 2019

\section{References}

1. Formica M, Zanirato A, Cavagnaro L, et al. What is the current evidence on vertebral body osteonecrosis? A systematic review of literature. Asian Spine J. 2018;12(3):586-99. https://doi.org/10.4184/asj.2018.12.3.586.

2. Kim HS, Ju Cl. Spinal instability predictive scoring system for subsequent fracture after bone cement augmentation in patient with osteoporotic 
vertebral compression fracture. World Neurosurg. 2017;106:1-10. https://doi. org/10.1016/j.wneu.2017.07.049.

3. Steel HH. Kümmell's disease. Am J Surg. 1951;81(2):161-7. https://doi.org/10. 1016/0002-9610(51)90206-1.

4. Kang MS, Shin YH, Lee CD, et al. Delayed neurological deficits induced by an epidural hematoma associated with a thoracic osteoporotic compression fracture. Neurol Med Chir (Tokyo). 2012;52(9):633-6. https://doi.org/10.2176/ nmc.52.633.

5. Lee SH, Cho DC, Sung JK. Catastrophic intramedullary hematoma following Ku"mmell's disease with large intravertebral cleft. Spine J. 2008:8:1007-10. https://doi.org/10.1016/.spinee.2007.07.397.

6. McKiernan F, Faciszewski T. Intravertebral clefts in osteoporotic vertebral compression fractures. Arthritis Rheum. May 2003;48(5):1414-9. https://doi. org/10.1002/art.10984.

7. Kim HS, Heo DH. Percutaneous pedicle screw fixation with

Polymethylmethacrylate augmentation for the treatment of thoracolumbar Intravertebral Pseudoarthrosis associated with Kummell's osteonecrosis. Biomed Res Int. 2016:1-7. https://doi.org/10.1155/2016/3878063.

8. Park SJ, Kim HS, Lee SK, et al. Bone cement-augmented percutaneous short segment fixation: an effective treatment for Kummell's disease? J Korean Neurosurg Soc. 2015;58(1):54-9. https://doi.org/10.3340/jkns.2015.58.1.54.

Ready to submit your research? Choose BMC and benefit from:

- fast, convenient online submission

- thorough peer review by experienced researchers in your field

- rapid publication on acceptance

- support for research data, including large and complex data types

- gold Open Access which fosters wider collaboration and increased citations

- maximum visibility for your research: over $100 \mathrm{M}$ website views per year

At $\mathrm{BMC}$, research is always in progress.

Learn more biomedcentral.com/submissions 